\title{
A Study of Patient-Physician Communication and Barriers in Communication
}

\author{
${ }^{1}$ Nikita Sabherwal, ${ }^{2}$ Ashok Mittal, ${ }^{3}$ NK Pandey, ${ }^{4}$ Ginny Kaushal, ${ }^{5}$ Paul Kaustav
}

\section{ABSTRACT}

Context: Effective doctor-patient communication is the basic requirement in building a good doctor-patient relationship. Safe practices and effective, patient-centered communication is key to quality care. Good doctor-patient communication has the potential to help regulate patients' emotions, facilitate comprehension of medical information and allow for better identification of patients' needs, perceptions and expectations. Doctors with better communication and interpersonal skills are able to detect problems earlier, can prevent medical crisis and expensive intervention, and provide better support to their patients.

Current research indicates that ineffective communication among healthcare professionals is one of the leading causes of medical errors and patient harm. There are many barriers to good communication in the doctor-patient relationship, including patients' anxiety and fear, doctors' burden of work, fear of litigation, fear of physical or verbal abuse, and unrealistic patient expectations. National accreditation board for hospitals and healthcare providers (NABH) standards and international patient safety goals focus on the importance of effective communication in healthcare settings and how it leads to patient safety.

This study is an attempt to identify gaps in patient physician communication in the current healthcare settings, find the barriers in communication and give recommendation to enhance good practices in the future.

Aims: The aim of the study is to analyze the current levels of effective patient communication in a tertiary care hospital in Delhi-NCR with help of a self-administered questionnaire. The study will assess the level of information shared with the patient.

Settings and design: The design of our proposed study is a descriptive study where we will use a self-administered

\footnotetext{
${ }^{1}$ Program Director, ${ }^{2}$ Director, ${ }^{3}$ Chairman, ${ }^{4}$ Lecturer

${ }^{5}$ Senior Research Associate

${ }^{1,4}$ Faculty of Healthcare Administration, Indian Institute of Learning and Advanced Development, Gurgaon, Haryana India

${ }^{2}$ Department of Independent, MetLife India Insurance Co. Ltd. New Delhi, India

${ }^{3}$ Department of Medical Administration, Asian Institute of Medical Sciences, Faridabad, Haryana, India

${ }^{5}$ Indian Institute of Learning and Advanced Development Gurgaon, Haryana, India
}

Corresponding Author: Nikita Sabherwal, Program Director Department of Healthcare Administration, 54 Navjiwan Vihar Opp Geetanjali Enclave, New Delhi-110017, India, Phone: 9810853225, e-mail: nikitasabherwal@gmail.com questionnaire to assess the level of patient-physician communication in the selected study setting.

Materials and methods: The NABH standard were used as a guideline for preparing the self-administered questionnaire. All admitted vulnerable patients of the selected study area will consist of the population for the study. Simple random sampling technique will be used to derive the sample out of the population.

Statistical analysis used: Correlation and analysis of variance (ANOVA) were used to establish associations between the independent and dependent variables.

Results: The study shows that $48 \%$ of the respondents were of opinion that they were given partial information, while $20 \%$ of the respondents alleged that they were not given any information about the explanation of their disease, its prognosis and the treatment option that were available, i.e. a total of $62 \%$ of the patients said that they had partial information to complete lack of information that would have made them aware of their diseases, its prognosis and the treatments options available to cure it, while only $32 \%$ of the patients agreed that they were supplied with thorough information during their interaction with the physicians.

Conclusion: The majority of the patients were not wellinformed about their disease, its prognosis, treatment plan and continuity of care. There was a significant positive correlation between the communication made at initial stages of hospital stay and during the end stages of stay of patient. The main barrier to patient physician communication was time.

Keywords: Barriers in communication, IPSG, NABH, Patientphysician communication.

Key message: To ensure patient safety, it is imperative to inform patients about all the important aspects starting from admission till discharge.

How to cite this article: Sabherwal N, Mittal A, Pandey NK, Kaushal G, Kaustav P. A Study of Patient-Physician Communication and Barriers in Communication. Int $\mathrm{J}$ Res Foundation Hosp Healthc Adm 2015;3(2):71-78.

\section{Source of support: Nil}

Conflict of interest: None

\section{INTRODUCTION}

Successful medical encounters require effective communication between the patient and the physician. 'Success' implies that the patient and physician have developed a 'partnership' and the patient has been fully educated in the nature of his or her condition and the different methods to address the problem. This allows the patient to be actively involved in the decision-making process and 
establishes agreed upon expectations and goals. ${ }^{1}$ Effective doctor-patient communication is the basic requirement in building a good doctor-patient relationship and to get better clinical outcomes. Safe practices and effective, patient-centered communication is key to quality care. Good communication is both an ethical imperative, necessary for informed consent and effective patient engagement, and a means to avoid errors, improve quality and achieve better and safer health outcomes. The ultimate objective of any doctor-patient communication is to improve the patient's health and medical care.

Good doctor-patient communication has the potential to help regulate patients' emotions, facilitate comprehension of medical information, and allow for better identification of patients' needs, perceptions and expectations. Doctors with better communication and interpersonal skills are able to detect problems earlier, can prevent medical crisis and expensive intervention, and provide better support to their patients. Effective patient physician communication leads to patient satisfaction. According to Shukla, ${ }^{10}$ doctor-patient communication is important since it leads to improved compliance with medical treatment, better health and functional status, enhanced clinician and patient satisfaction and also reduces risk of medical malpractices. It is observed in hospitals that when patient physician appointments are of longer durations, doctors ask significantly more questions and make more statements explaining the problem and its management, while patients ask significantly more questions and make more statements of their own ideas about the problem. The entire process from entry to discharge has to be completed within a stipulated time frame and hence it becomes imperative for all the crucial communications to be made within that time with regard to treatment plan, possible complications, medication, prevention techniques, etc.

Kirstein Weir comments on how effective communication is linked to many positive medical outcomes. Research shows 'good communication is associated with patient adherence to treatment, control of symptoms, control of pain and patient satisfaction.' Informed patients are also more likely to decline elective surgeries and disease screenings that could lead to risks from false positives and unnecessary interventions (Weir 2012). ${ }^{11}$ has pointed out that most of the studies reviewed demonstrated a correlation between effective physician-patient communication and improved patient health outcomes. The components of effective communication identified by these studies can be used as the basis both for curriculum development in medical education and for patient education programs. Future research should focus on evaluating such educational programs. ${ }^{11}$
Current research indicates that ineffective communication among healthcare professionals is one of the leading causes of medical errors and patient harm. Research conducted during the 10 years period of 1995 to 2005 has demonstrated that ineffective team communication is the root cause for nearly $66 \%$ of all medical errors during that period. This means that when healthcare team members do not communicate effectively, patient care often suffers. In his work, ' 5 side-effects of Ineffective Communication', Hicks ${ }^{5}$ said that incomplete or inaccurate patient records and communication breakdowns can have serious consequences for the medical office and its patients. One vital piece of information not communicated can have disastrous results. Although some mishaps are unavoidable, effective communication can result in better outcomes for patients and the overall success of the medical office. Further, medical error vulnerability is increased when healthcare team members are under stress, are in high-task situations, and when they are not communicating clearly or effectively. ${ }^{4}$ A review of reports from the Joint Commission reveals that communication failures were implicated at the root of over $70 \%$ of sentinel events (Joint Commission on Accreditation of Healthcare Organizations, 2005). In another study, conducted to examine factors that prompted families to file malpractice claims against doctors following perinatal injuries, it was shown that communication was an important factor that was related to these malpractice claims. The same authors also found that physicians who had been sued frequently were also the ones who received frequent complaints regarding the interpersonal care that they provided for patients, even by patients that never sued. The complaints from these patients included 'a feeling of being rushed', 'being neglected' and a lack of explanations for tests performed. ${ }^{10}$ Other barriers to good communication in the doctor-patient relationship, include patients' anxiety and fear, doctors' burden of work, fear of litigation, fear of physical or verbal abuse, and unrealistic patient expectations.

According to Huntington and Kuhn, ${ }^{6}$ the 'root cause' of malpractice claims is a breakdown in communication between physician and patient. Previous researches that examined plaintiff depositions found that $71 \%$ of the malpractice claims were initiated as a result of a physician-patient relationship problem. Closer inspection found that most litigious patients perceived their physician as uncaring. The same researchers found that one out of four plaintiffs in malpractice cases reported poor delivery of medical information, with $13 \%$ citing poor listening on the part of the physician. 3,6 Interviews with patients who have filed malpractice suits against their physicians often site poor communication and lack of empathy as a factor in pursuing legal action. ${ }^{2}$ 
National Accreditation Board for Hospitals and Healthcare providers (NABH) standards provide framework for ensuring patient safety and quality of patient care. The international patient safety goals also emphasizes the importance of effective communication in delivery of safe and effective patient care. This study aims to analyze the current levels of effective patient communication in a tertiary care hospital in DelhiNCR with help of a self-administered questionnaire. The study will assess the level of information shared with the patient. Many models have been developed to assist healthcare providers in developing approaches to improve their ability to communicate with their patients. These models focus on improvement in the quality of the encounter and do not necessarily require any significant increased investment in the length of the encounter. These approaches have been demonstrated to improve patient satisfaction and also allow the provider to demonstrate empathy, concern and humanism. ${ }^{3}$ It is clear from the study done by Kurtz et $\mathrm{al}^{9}$ that better physician communication skills improve patient satisfaction and clinical outcomes and that good communication skill can be taught and learned. It is important that physicians learn the principles of good physician-patient communication and apply them in clinical practice. Medical education programs at all levels should include teaching of physician-patient communication. ${ }^{9}$

The reference for designing the questionnaire of this study is taken from patient rights and education (PRE). The chapter PRE specially emphasizes on the importance of communication and also has identified key areas of communication which are important for patients.

\section{RESEARCH DESIGN}

The current study was conducted at a super-specialty hospital. A descriptive research design was utilized in the current study. This design is concerned with description of a phenomenon of interest and focused on a single group or population characteristics without trying to make interference. A sample of convenience including 70 patients, representing all those who are admitted in the IPD units of the selected study setting was taken. A structured questionnaire was developed, tested for clarity and feasibility, and then used to collect data. Development of this questionnaire was guided by NABH Standards (Patient Rights and Education Chapter). Designed tools were examined for content validity by a panel of five experts.

\section{Ethical Clearance and Confidentiality}

The current study was approved by ethical committee of the selected Hospital. Confidentiality and anonymity of each subject were assured through coding of all data.

\section{METHODOLOGY}

The current study was conducted in two phases: the preparation phase and implementation phase. As regards to the preparation phase, it was concerned with construction and preparation of data collection tools, in addition to obtaining managerial agreement to carry out the study. This phase lasted for about 4 months. Concerning the implementation phase, it was carried out after obtaining official permissions to carry out the study. Data of the current study were collected over a period of 4 months starting from Oct 2014 to Jan 2015. The researcher/research associate was available during the time of filling the data collection sheet to answer any question, and to provide the needed explanations. Filling the questionnaire required about 15 minutes from each patient. Obtained data were fed into Microsoft Excel for further analysis.

The questionnaire had two parts: Part 1 was aimed to record the demographic details, i.e. gender and age of the respondents, while part 2 of the questionnaire had 14 questions pertaining to patient-physician communication. Fourteen questions were categorized into four categories: Patient-awareness communication (3 questions), patient-care communication (4 questions) which included patient-physician question pertaining to initial and regular assessment and treatment-related communication between patients and physician, patientdischarge communication (4 questions) and patient-rights communication (2 questions) which included education about patient and family rights.

\section{RESULTS AND DISCUSSION}

Table 1 presents the descriptive statistics for patient communication. There were 14 questions pertaining to patient communication and 70 respondents were picked up for the survey. Maximum score for each question was 3 , i.e. maximum possible score that could be scored from 14 questions was 42 . However, the mean score was 29.80 which indicated a gap in the patient communication. Low standard error of 0.89 along with low skewness of -0.14 further indicated low variance among the responses, i.e. there was uniformity among the patients' responses.

\section{Patient Communication}

Graph 1 shows that $62 \%$ of the patients said that they had partial information to complete lack of information that would have made them aware of their diseases, its prognosis and the treatments options those were available to cure it, while only $32 \%$ of the patients agreed that they were supplied with thorough information during their interaction with the physicians. As many as $48 \%$ of the respondents were of opinion that they were 
Table 1: Descriptive statistics for patient communication

\begin{tabular}{ll}
\hline $\mathrm{N}=$ Number of questions & 14.00 \\
Maximum possible score & 42.00 \\
Mean & 29.80 \\
Standard error & 0.89 \\
Skewness & -0.14 \\
Range & 23.00 \\
Minimum & 18.00 \\
Maximum & 41.00 \\
Count = Number of respondents & 70.00 \\
\hline
\end{tabular}

given partial information, while $20 \%$ of the respondents alleged that they were not given any information about the explanation of their disease, its prognosis and the treatment option those were available.

The above pie diagram depicts the overall scenario of patient communication while the below subsections are dedicated for more in-depth analysis of patient communication.

\section{Patient-awareness Communication}

Graph 2 shows that as high as $60 \%$ of the patients accepted that they received partial information which could make them aware of their diseases and treatment options and $17 \%$ of the respondents alleged that they were not given information. Only $23 \%$ of the patients agreed that they were supplied with thorough information during their interaction with the physicians. Thus out of every 100 patients, 77 patients remain unaware of their diseases and treatment options, which is a matter of concern for the patients' well-being.

Graph 3 gives a more detailed scenario of the patient awareness communication. Majority of the patients accepted that they were given only partial information for all the questions related to 'patient awareness regarding medical conditions' (That is AW1 'Have you

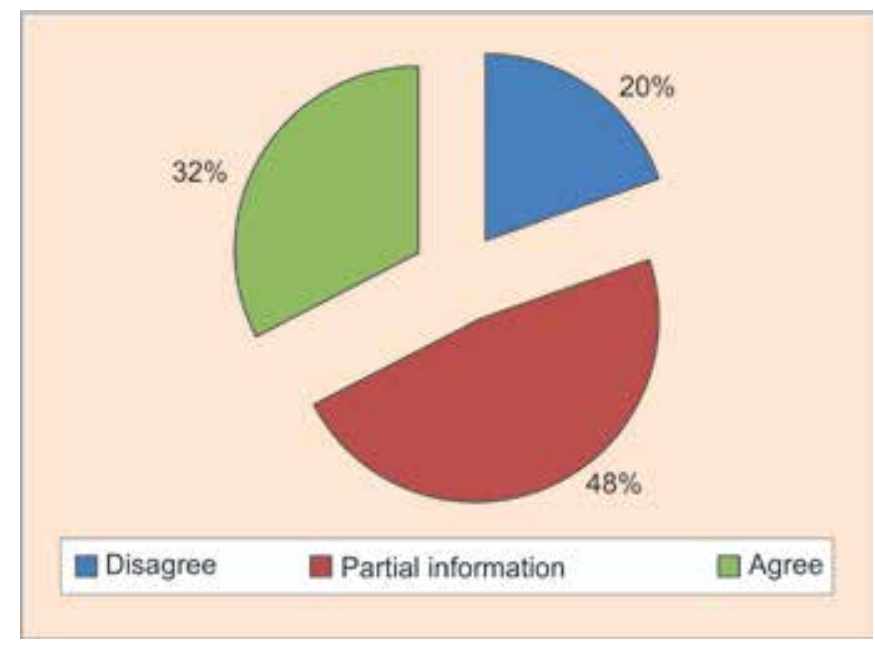

Graph 1: Patients' responses on patient communication been explained about your medical condition?', AW2, 'Have you been explained about the prognosis of your medical condition?' and AW3 'Have you been told about the treatment options available?'). For the question, 'Have you been explained about your medical condition?', 56\% of the patients said that the physician did not explain their disease fully to them, while as many as $50 \%$ said they were not being explained clearly about the prognosis of their disease. A staggering $74 \%$ of the patients said that they were not given complete information about the treatment options that were available. For each case, 23,27 and $20 \%$ of the patients agreed that they received complete information. Hence, 77,73 and $80 \%$ patients had partial to no information about their disease, prognosis of their disease and the treatment options available.

\section{Patient-care Communication}

From Graph 4 , it can be found that $62 \%$ of the patients proceed with the treatment without having complete knowledge of the aspects that are related to the treatment procedure.

Graph 4 shows that $38 \%$ of the patients agreed that they were supplied with thorough information during their interaction with the physicians regarding the treatment procedure and the aspects related to it, while $36 \%$ of the patients said that they received partial information related to treatment procedure, associated risks of the treatment, the duration of the treatment and the part/pre-preparation that needs to be done for the treatment while $26 \%$ of the respondents alleged that they were not given any information.

Graph 5 gives a more detailed scenario of the patientcare communication. While 43 and $44 \%$ of the patients agreed to that they were given complete explanation of their treatment procedure and the duration of it, only $25 \%$ of the patients accepted that they were given complete

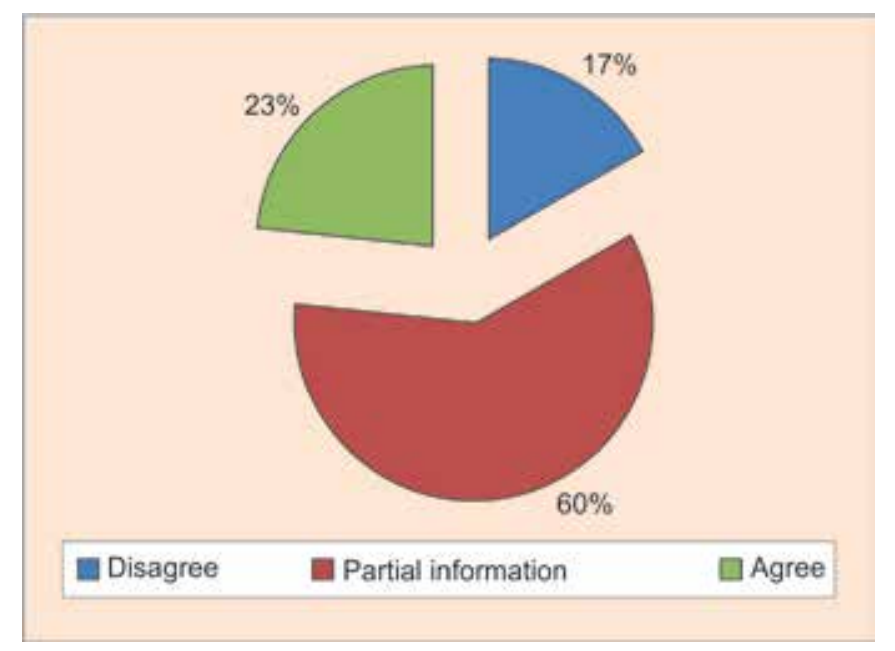

Graph 2: Patients' responses on patient awareness communication 


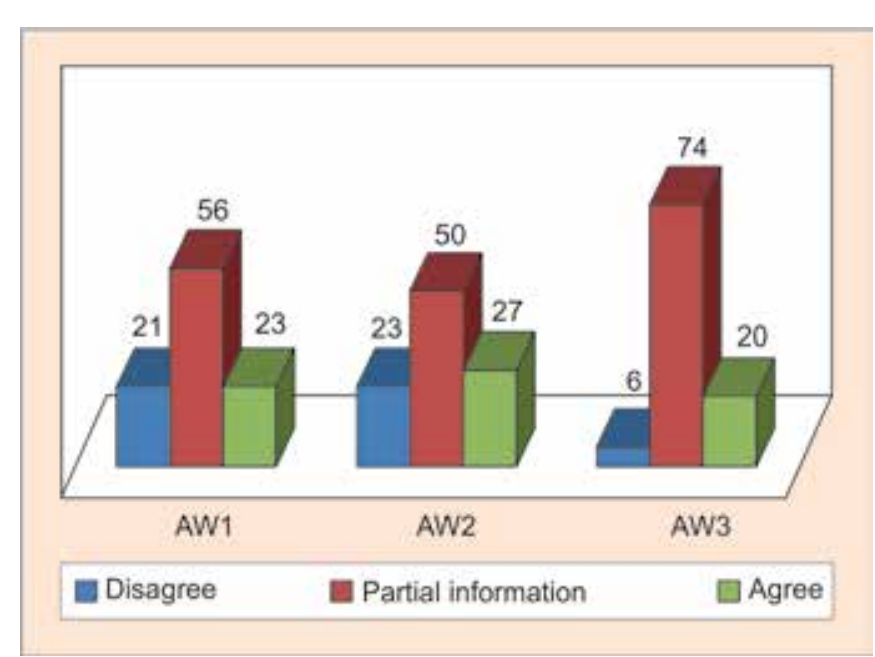

Graph 3: Percentage distribution of responses on patient awareness communication

knowledge of the associated risks of their treatment procedure, i.e. as high as $75 \%$ of the patients went ahead with the treatment procedure without having adequate information of the associated risks and hazards of their treatment procedure, of which $29 \%$ of the patients were not given any information and $46 \%$ of them were given superficial information. Thirty-nine percent of the patients accepted that they knew about the part/prepreparations that should be done before the treatment while $27 \%$ of them said they had no information at all and $34 \%$ said that they had partial knowledge. Hence, $61 \%$ patients were without proper information about the part/ pre-preparation that needed to be done before treatment.

\section{Patient-discharge Communication}

Graph 6 shows that 33\% of the patients accepted that they were given complete information about the lifestyle they should follow, the diet they should follow and the medicines they should take along with their timings, i.e.

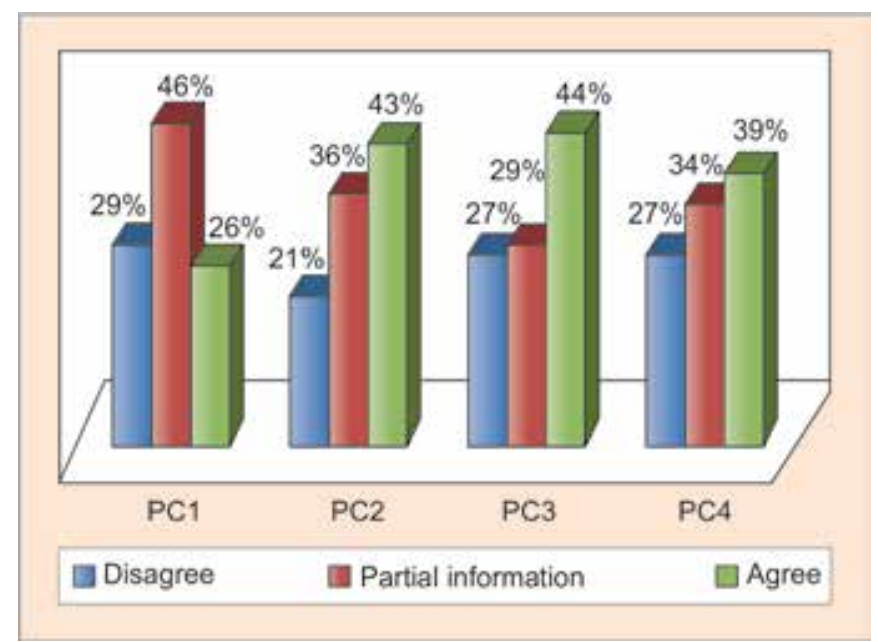

Graph 5: Percentage distribution of responses on patient care communication

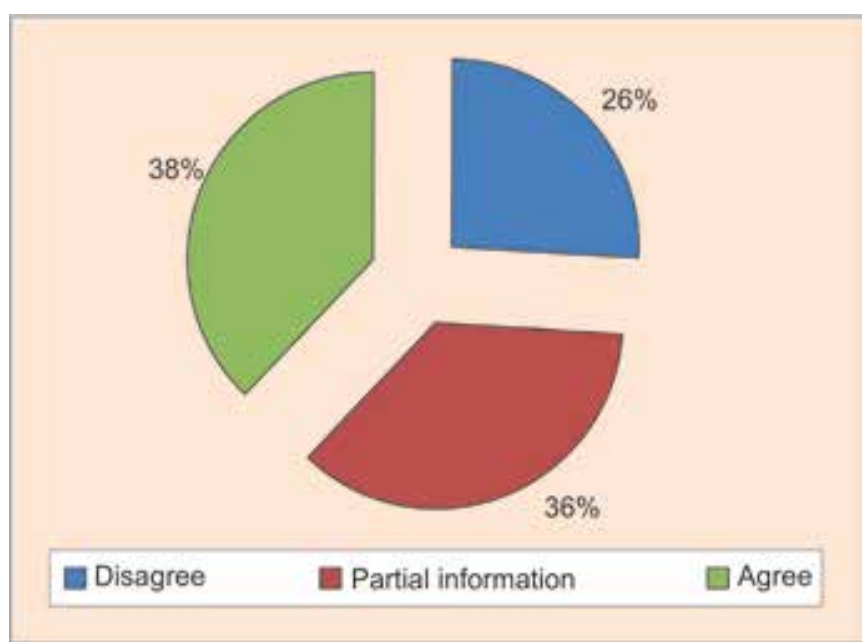

Graph 4: Patients' responses on patient care communication

$67 \%$ of the patients admitted they left the healthcare unit without complete information of which, 19\% said they were not given any advice while $48 \%$ of the patients said they were given partial information about the lifestyle and diet after discharge, along with the medicines that they must have with the timings of the medicines as well.

Graph 7 gives a more detailed scenario of the patientdischarge communication. A total of $44 \%$ of the patients agreed that they had complete information about the precautions that they should follow after discharge, $47 \%$ of the patients said that they had only partial information about it, while $9 \%$ said that they had no information at all. A total of $66 \%$ of the patients had partial information about the medicines that should follow and about the interaction of the drugs with the patients, while $34 \%$ agreed that they had complete information. The 33 and $32 \%$ of the patients had complete knowledge about the possible side effects of the medicines and the diet that they should follow, i.e. $67 \%$ of the patients were

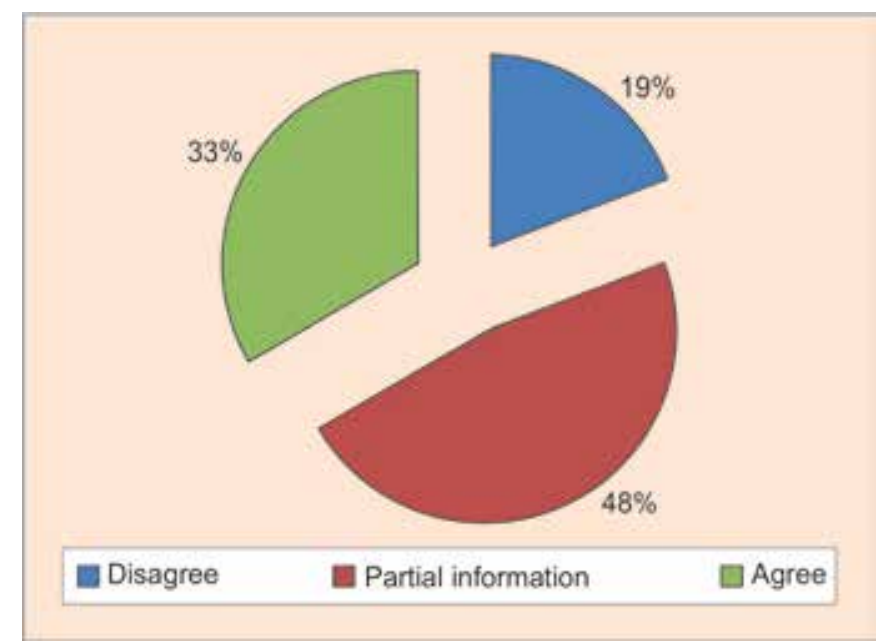

Graph 6: Patients' responses on patient discharge communication 
not completely aware of the possible side effects of the medicines, of which $11 \%$ had no information at all while $56 \%$ of the patients accepted that they were given partial information about it.

\section{Patient-rights Communication}

Graph 8 shows that $33 \%$ of the patients accepted that they were given complete information about their rights as the patients which implies that. A total of $67 \%$ of the patients admitted they left the healthcare unit without complete information of which, $12 \%$ said they did not receive any education on patient rights while $55 \%$ of the patients said they were given partial information about their rights and claims as the patients.

Graph 9 gives a more detailed scenario of the patient rights communication. A total of $37 \%$ of the patients agreed that they had complete information about the procedure to obtain urgent follow-up. A total of $49 \%$ of the patients said that they had only partial information about it, while $14 \%$ said that they had no information at all. A total of $61 \%$ of the patients had partial information about their rights and responsibilities, while $29 \%$ agreed that they were completely aware of it. However, $10 \%$ of the patients said that they had no information about their rights and responsibilities.

Hypothesis 1 (H1): There is an association among patient awareness communication, patient care communication, patient discharge communication and patient rights communication.

Table 2 suggested that there were moderate to high degree of positive linear association among patient awareness communication, patient care communication, patient discharge communication and patient rights communication.

Hypothesis 2 (H2): Age of the patients has an impact on patient communication.

Table 3 suggests that age of the patients impacted their communication with the physician. The Table 3 suggested that the scores of the patients with in the age groups 20 to 30 years and 30 to 40 years were higher than the patients between the age groups below 20 years and above 40 years. This could be due to the reason that
Table 2: Correlation among patient awareness communication, patient care communication, patient-discharge communication and patient-rights communication

\begin{tabular}{lllll}
\hline & $\begin{array}{l}\text { Patient } \\
\text { awareness }\end{array}$ & $\begin{array}{l}\text { Patient } \\
\text { care }\end{array}$ & $\begin{array}{l}\text { Patient } \\
\text { discharge }\end{array}$ & $\begin{array}{l}\text { Patient- } \\
\text { rights }\end{array}$ \\
\hline $\begin{array}{l}\text { Patient } \\
\text { awareness }\end{array}$ & 1.00 & - & - & - \\
$\begin{array}{l}\text { Patient care } \\
\begin{array}{l}\text { Patient- } \\
\text { discharge }\end{array}\end{array}$ & 0.78 & 1.00 & - & - \\
Patient-rights & 0.71 & 0.89 & 1.00 & - \\
\hline
\end{tabular}

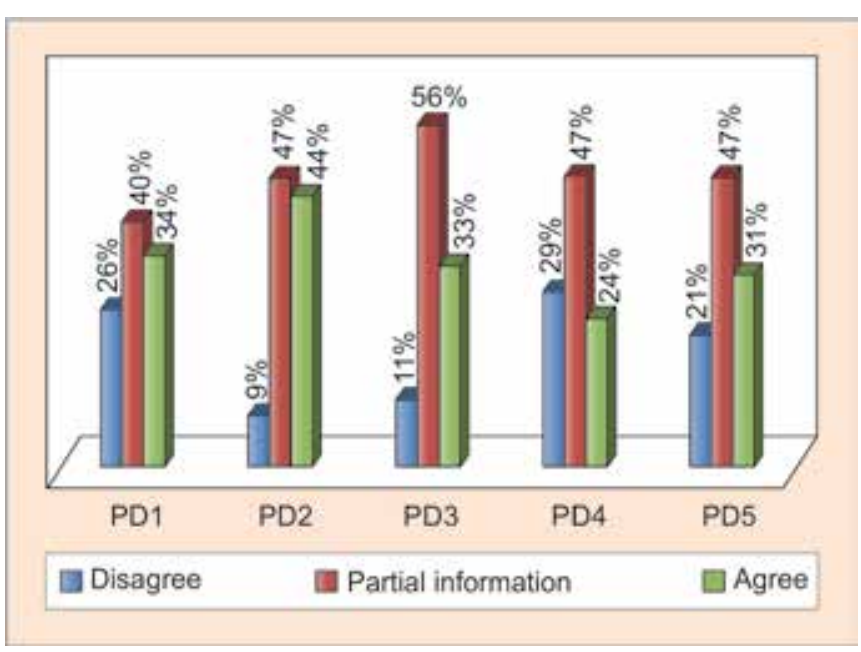

Graph 7: Percentage distribution of responses on patient-discharge communication

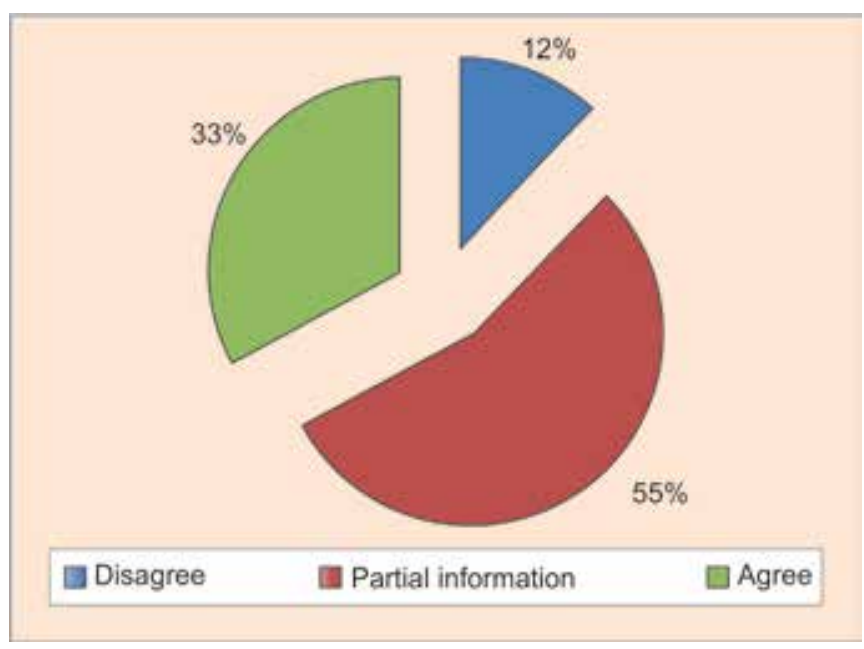

Graph 8: Patients' responses on patient-rights communication

Table 3: ANOVA results_-impact of age on patient awareness communication, patient care communication, patient discharge communication and patient rights communication

\begin{tabular}{lllllll}
\hline Groups & Count & PA mean & PC mean & PD mean & PR mean & Allover \\
\hline Below 20 & 7 & 4.86 & 5.71 & 7.00 & 3.14 & 20.71 \\
20-30 & 15 & 7.40 & 9.73 & 12.73 & 5.07 & 34.93 \\
30-40 & 23 & 7.22 & 11.48 & 13.30 & 5.30 & 37.30 \\
Above 40 & 25 & 4.92 & 5.72 & 8.16 & 3.56 & 22.36 \\
\hline F-statistics & & 38.74 & 182.62 & 139.07 & 44.43 & 388.17 \\
p-values & & 0.000 & 0.000 & 0.000 & 0.000 & 0.000 \\
\hline
\end{tabular}




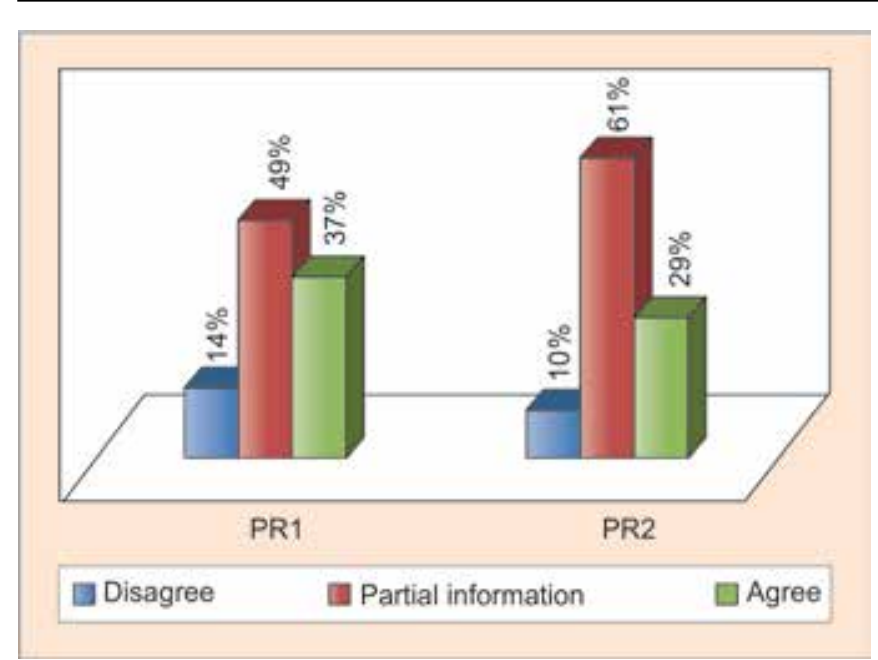

Graph 9: Percentage distribution of responses on patient-rights communication

patients who were between 20 and 30 years and 30 to 40 years were young and they were more aware of the everything around them, and hence could understand things from a better perspective and might have asked questions to clear their doubts, while the patients who were above 40 years were relatively elder and they might not have asked questions to clear doubts.

Hypothesis 3 (H3): Gender has an impact on patient communication.

Table 4 depicts the impact of gender of the patient upon their communication with the physician. The Table 4 indicates that though gender has no role for the majority of patient-physician communication; however, it has an impact upon patient awareness communication, where the scores of the male patients were significantly higher than the female counterparts.

\section{BARRIERS IN COMMUNICATION}

Table 5 and Graph 10 depict the patients' responses on factors those were possible barriers in effective communication with the physician. When the patients

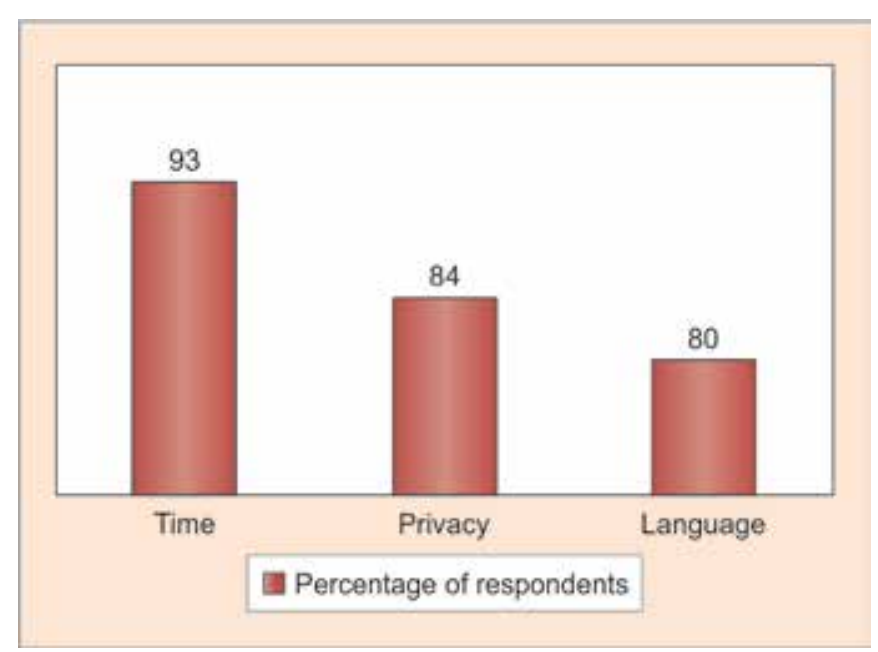

Graph 10: Percentage of responses on barriers in communication
Table 4: Independent t-test results-impact of gender on patient awareness communication, patient care communication, patient discharge communication and patient rights communication

\begin{tabular}{|c|c|c|c|c|c|}
\hline \multicolumn{6}{|c|}{ Impact of gender on patient communication: $t$-test } \\
\hline & \multicolumn{2}{|c|}{ Mean score } & \multirow[b]{2}{*}{ Difference } & \multirow[b]{2}{*}{ t-statistics } & \multirow[b]{2}{*}{$p$-value } \\
\hline & Male & Female & & & \\
\hline $\begin{array}{l}\text { Patient } \\
\text { awareness } \\
\text { communi- } \\
\text { cation }\end{array}$ & 6.179 & 4.024 & 2.155 & 6.674 & 0.000 \\
\hline $\begin{array}{l}\text { Patient care } \\
\text { communi- } \\
\text { cation }\end{array}$ & 8.429 & 8.500 & -0.071 & -0.105 & 0.917 \\
\hline $\begin{array}{l}\text { Patient } \\
\text { discharge } \\
\text { communi- } \\
\text { cation }\end{array}$ & 10.679 & 10.738 & -0.060 & -0.086 & 0.932 \\
\hline $\begin{array}{l}\text { Patient } \\
\text { rights com- } \\
\text { munication }\end{array}$ & 4.571 & 4.310 & 0.262 & 0.991 & 0.325 \\
\hline $\begin{array}{l}\text { All over } \\
\text { patient } \\
\text { communi- } \\
\text { cation }\end{array}$ & 29.857 & 29.762 & 0.095 & 0.052 & 0.959 \\
\hline
\end{tabular}

Table 5: Barriers in communication

\begin{tabular}{llll}
\hline No. of respondents & Time & Privacy & Language \\
\hline & 65 & 59 & 56 \\
\hline
\end{tabular}

were being asked about the barriers in their interaction with the physician, most of the patients chose more than one option out of the three options they were given. A total of $93 \%$ of the patients (65 out of 70 ) said that the physician did not give them enough time to interact and was in a hurry to get over with the session, while $84 \%$ of the patients (59 out of 70) said that they could not discuss their matter at length with the physician since they felt too shy to talk about it and felt that their privacy might be breached. A total of $80 \%$ of the patients (56 out of 70 ) said language was the barrier in their interaction with the physician.

\section{CONCLUSION}

Hence, the findings of the study reveal that majority of the patients were not informed about the crucial information required at different stages of patient care process. As supported by various studies ${ }^{7-9}$ an effective patient physician communication leads to better patient care while lack of physician-patient communication can compromise with the safety of patients.

\section{ACKNOWLEDGMENTS}

We are thankful to the following authors for their past literary inputs which helped the authors of these papers 
to conceptualize the subject and have acted as the guiding force for this article:

- Clever SL, Jin L, Levinson W, Meltzer D. Does doctorpatient communication affect patient satisfaction with hospital care? Results of an analysis with a novel instrumental variable. Health Services Res 2008;43(Part I):5.

- Khan TM, Hassali MA, Al-Haddad M. Patientphysician communication barrier: a pilot study evaluating patient experiences, young Pharm 2011 Jul-Sep;3(3):250-255.

- Larson, EB, Yao X. Clinical empathy as emotional labor in the patient-physician relationship. J Am Med Assoc 2005;293(9):100-1106.

- Lingard LS, Espin S, Whyte G, et al. Communication failures in the operating room: an observational classification of recurrent types and effects. Qual Saf Health Care 2004;13: 330-334.

- Leonard M, Graham S, Bonacum D. The human factor: the critical importance of effective teamwork and communication in providing safe care. Qual Saf Health Care 2004.

- Mathew JE, Azariah J, George SE, Grewal SS. Assessing the effectiveness of communication to families of critically ill patients. J Anaesthesiol Clin Pharmacol 2015;31(1).

- Peterson MC, Holbrook J, Von Hales D, Smith NL, Staker LV. Contributions of the history, physical examination and laboratory investigation in making medical diagnoses. Western J Med 1992;156:163-165.

- Press Ganey Associates. Friendliness/courtesy of physician 2009.

- Schattner A. The silent dimension: expressing humanism in each medical encounter. Arch Intern Med 2009;169:1095-1099.

- Tongue J, Epps H, Forese L. Communication skills for patient centered care; research-based, easily learned techniques for medical interviews that benefit orthopedic surgeons and their patients. J Bone Joint Surg Am 2005;87:652-658.

- Alexander G, Casalino LP, Tseng CW, McFadden D, Meltzer D. Barriers to patient-physician communication about outof-pocket costs. J Gen Int Med 2004;19: 856-860.

\section{REFERENCES}

1. Arora NK. Interacting with cancer patients: the significance of physicians' communication behavior. Soc Sci Med 2003; 57791-57806.

2. Bhattacharyya T, Yeon H, Harris MB. The medical-legal aspects of informed consent in orthopaedic surgery. Bone Joint Surg AM 2005;87:652-658.

3. D'Ambrosia, R. Orthopedics in the New Millennium, a new patient-physician partnership. J Bone Joint Surg AM 1999;8(4): 447-451.

4. Department of Defense and Agency for Healthcare Research and Quality, Team strategies and tools to enhance performance and patient safety. Available at: http://www. ahrq.gov/qual/teamstepps/.

5. Hicks J. Side-effects of ineffective communication. Available at: http://medicaloffice.about.com/od/leadershipresources/ tp/5-Side-Effects-Of-Ineffective-Communication.htm

6. Huntington B, Kuhn N. Communication gaffes: a root cause of malpractice claims. Baylor University Medical Center Proceedings 2003; 16:157-161.

7. Improving America' S Hospitals: a report on quality and safety, 2005, (2007), The Joint Commission.

8. Kirsten W. Improving patient-physician communication 2012; 43(10). Available at: http://www.apa.org/monitor/2012/11/ patient-physician.aspx

9. Kurtz SM. Doctor-patient communication: principles and practices. Neurol Sci 2002;29(2):S23-S29. Available at: http:// www.ncbi.nlm.nih.gov/pubmed/12139082

10. Shukla A. Doctor-patient communication: an important but often ignored aspect in clinical medicine. JIACM 2010;11(3): 208-211.

11. Stewart MA. Effective physician-patient communication and health outcomes: a review. CMAJ 1995;152(9):1423-1433. Available at: http://www.ncbi.nlm.nih.gov/pubmed/7728691. 